\title{
COMUNICAÇÃO
}

\section{COMPARAÇÃO ENTRE LEISHMANIA ISOLADAS DE PACIENTES DE TRÊS BRAÇOS, BAHIA, E DE DIVERSAS REGIÕES, ATRAVÉS DE SEU COMPORTAMENTO NO TUBO DIGESTIVO DE LUTZOMYIA LONGIPALPIS (PSYCHODIDAE, PHLEBOTOMINAE)}

\author{
Julio A. Vexenat, Air C. Barretto, Cesar C. Cuba e Philip D. Marsden.
}

Há vários métodos para a caracterização de estoques de Leishmania com a finalidade de sua identificação especifica ou subespecífica. Assim, existem os métodos baseados na morfologia 12 , comportamento biológico 67 , bioquímico 3410 e imunológico 9 . Os métodos biológicos abrangem: 1) o crescimento do parasito em meios artificiais, 2) a inoculação em hamster e posterior observação da evolução da lesão e 3) infecção experimental de Lutzomyia longipalpis (flebotomineo) e observacão da evolução do parasito em seu tubo digestivo. Este último método é utilizado para separar principalmente o complexo Mexicana, de comportamento suprapilária ou seja uma infecção restrita ao intestino médio e anterior, sem atingir o triângulo posterior, do complexo Braziliensis de evolução peripilária, cuja infecção atinge o triângulo posterior do tubo digestivo do flebotomíneo, observando-sè em algumas infecçòes a ocupação do parasito em todo o trato digestivo do inseto 58 .

Uma colônia de Lutzomyia longipalpis (Lutz e Neiva, 1912), originada do Ceará e mantida no Instituto Evandro Chagas em Belém (Pará) foi adaptada no Laboratório de Parasitologia Médica da Universidade de Brasilia, com a finalidade de ser utilizada para caracterização de estoques de Leishmania.
Neste trabalho são mostrados os resultados obtidos em 67 estoques isolados de pacientes de Três Braços, Bahia e 23 estoques isolados de pacientes registrados em dois hospitais (Hospital de Sobradinho e Presidente Médici) de Brasília, DF. A principal diferença entre os dois grupos é que o primeiro é composto de pacientes autóctones de Três Braços, Bahia e o segundo é formado de pacientes de diferentes regiões do país, em sua maioria oriundos dos Estados de Goiás, Minas e oeste do Estado da Bahial1.

Os flebotomíneos foram infectados em lesões de hamsters inoculados com material colhido por biópsia de lesões de pacientes, e cuidadosamente dissecados após 4 a 5 dias a fím de se observar o padrão de desenvolvimento do parasito no tubo digestivo do inseto.

Os resultados são mostrados na Tabela 1 . Cinco de 23 isolados de pacientes dos Hospitais $(21,7 \%)$ e apenas um de 67 pacientes de Três Braços, Bahia, (aproximadamente $1,5 \%$ ) tiveram comportamento suprapilária ou seja são pertencentes ao complexo Mexicana. O comportamento peripilária (Complexo Braziliensis) foi verificado em isolados de $18 / 23$ pacientes dos Hospitais $(78,2 \%)$ e de $65 / 67$ pacientes de Três Braços $(97,0 \%)$. Em apenas um isolado de paciente de Três Braços não foi possivel determinar o

Tabela 1 - Padrões de desenvolvimento de Leishmania, isoladas de pacientes, em tubo digestivo de Lutzomyia longipalpis (Psychodidae, Phlebotominae).

\begin{tabular}{lcccccccc}
\hline Origem dos Pacientes No de & \multicolumn{3}{c}{ Padrões de Desenvolvimento } & \multicolumn{3}{c}{ Falha de Infecçáo do inseto } \\
& Isolados & Suprapilaria & $(\%)$ & Peripilaria & $(\%)$ & N.o & $\%$ \\
\hline Três Braços, Bahia & 67 & 1 & $(1,49)$ & 65 & $(97,0)$ & 1 & $(1,49)$ \\
Hospitais Brasilia, DF & 23 & 5 & $(21,7)$ & 18 & $(78,2)$ & - & - \\
\hline Total & 90 & 6 & $(6,6)$ & 83 & $(92,2)$ & 1 & $(1,1)$ \\
\hline
\end{tabular}

Trabalho realizado com o auxilio financeiro do Conselho Nacional de Desenvolvimento Cientifico e Tecnológico (CNPq) 403690/82, U.S. Public Health Service AI 16282 e Ministério da Saúde (SUCAM).

Faculdade de Ciências da Saúde - Núcleo de Medicina Tropical e Nutrição, Universidade de Brasilia, DF, 70910 Brasilia, Brasil.

Recebido para publicação em $6 / 3 / 85$ padrão de evolução por não se ter conseguido infecção do inseto. $O$ posterior estudo da maioria desses isolados, através de métodos de cultivo, bioquimicos e imunológicos para determinação de subespécies do parasito, confirmaram os complexos previamente identificados através da infecção de flebotomineos, demonstrando assim o valor desse método para a separação dos dois complexos. Observa-se também a 
quase total predominância de parasitos do complexo Braziliensis na região de Três Braços, onde a leishmaniose humana com comprometimento mucoso é comum ${ }^{1}$, e onde casos humanos por Leishmania do complexo Mexicana é raro ${ }^{2}$. No grupo de pacientes dos hospitais, provenientes de vasta área dos Estados de Minas Gerais, Goiás e oeste da Bahia, apesar de predominar parasitos do Complexo Braziliensis, há um número significante $(21,7 \%)$ de pacientes portadores de Leishmania do Complexo Mexicana.

A utilização desse método, de simples execução, desde que se tenha uma colônia de L. longipalpis, é de grande valor para a identificação correta dos complexos de Leishmania, sobretudo em pacientes que procuram os hospitais, não somente pelas implicações clínicas distintas, causadas por esses grupos de parasito, como também para se conhecer as áreas onde eles predominam.

\section{REFERÊNCIAS BIBLIOGRÁFICAS}

1. Barretto AC, Cuba CC, Marsden PD, Vexenat JA, De Belder M. Caracteristicas epidemiológicas da leishmaniose tegumentar americana em uma região endêmica do Estado da Bahia, Brasil. I. Leishmaniose humana. Boletin de la Oficina Sanitária Panamericana 90:415-424, 1981.

2. Cuba CC, Barretto AC, Marsden PD. Leishmania Mexicana: Aspectos taxonómicos y rareza de la infección humana en Três Braços-Bahia, Brasil. Revista Sociedade Brasileira Medicina Tropical 17: 115-122, 1984.

3. Gardener PJ. Chance ML, Peters W. Biochemical taxonomy of Leishmania II. Electrophoretic variation on malate dehydrogenase. Annals of Tropical Medicine and Parasitology 68: 317-335, 1974.

4. Godfrey DF. Biochemical characterizations in the ta- xonomy of parasitic Protozoa. In: Proceding of Workshop Pan American Health Organization Biochemical Characterization of Leishmania. Washington, p. 62-79, 1982.

5. Killick-Kendrick R, Molyneux DH, Hommel M, Leany AJ, Robertson E. Leishmania in phlebotomid sandflies $\mathrm{V}$. The nature and significance of infections of pylorus and ileum of the sandfly by leishmaniae of the braziliensis complex. Proceedings of the Royal Society of London Série B, 198: 191-199, 1977.

6. Lainson R, Shaw JJ. Leishmaniasis of the New World: taxonomic problems. British Medical Bulletin 28:4448,1972

7. Lainson R, Shaw JJ. Las leishmanias y las leishmaniosis del Nuevo Mundo, con particular referencial al Brasil. Bulletin Pan American Health Organization 76: 93114. 1974.

8. Lainson R, Ward RD, Shaw JJ. Leishmania in flebotomid sandflies. VI Importance of hindgut development in distinguishing between parasites of the Leishmania mexicana and $L$. braziliensis complexes. Proceedings of the Royal Society of London 199: 309-320, 1977.

9. McMahon-Pratt D, David JR. Monoclonal antibodies that distinguish between New World species of Leishmania. Nature 291: 581-583, 1981.

10. Miles MD, Lainson R, Shaw JJ, Povoa M, Souza AA. Leishmaniasis in Brazil. XV. Biochemical distinction of Leishmania mexicana amazonensis, L. braziliensis braziliensis and $L$. braziliensis guyanensis aetiological agents of cutaneous Leishmaniasis in the Amazon Basin of Brazil. Transactions of the Royal Society of Tropical Medicine and Hygiene 75: 524-529, 1981

11. Sampaio RNR. Tratamento hospitalar de leishmaniose cutaneomucosa. Tese de Mestrado, Universidade Federal de Minas Gerais, Belo Horizonte. 1984.

12. Shaw JJ, Lainson R. Leishmaniasis in Brazil. XI. Observations on the morphology of Leishmania of the braziliensis and mexicana complexes. Journal of Tropical Medicine and Hygiene 79: 9-13. 1976. 